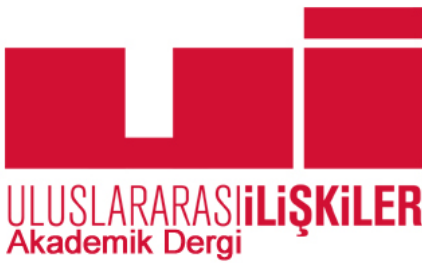

Yayın ilkeleri, izinler ve abonelik hakkında ayrıntılı bilgi:

E-mail: bilgi@uidergisi.com.tr

Web: www.uidergisi.com.tr

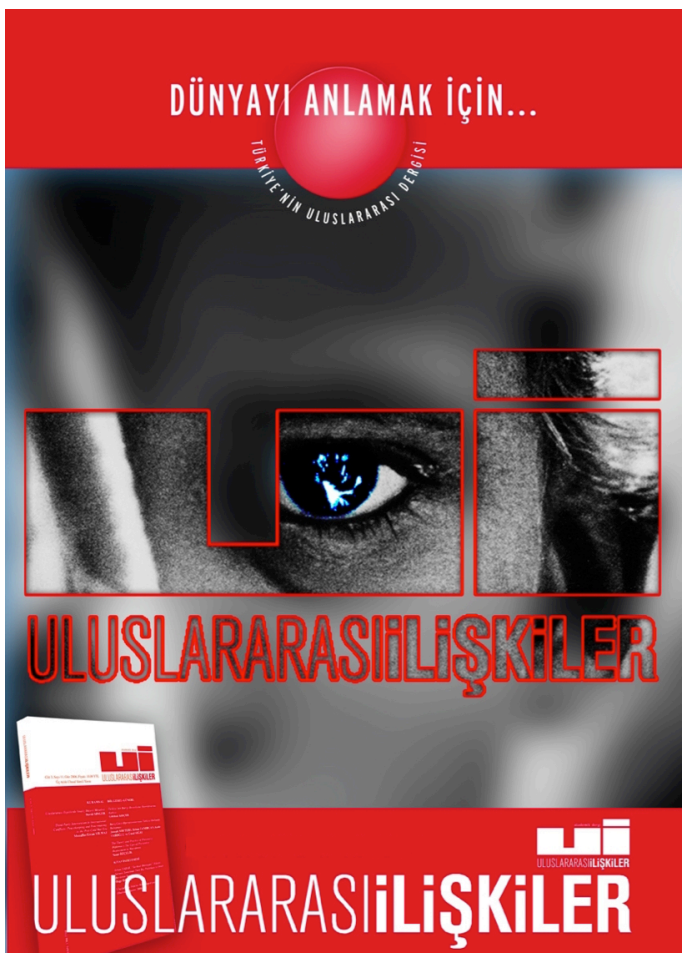

\author{
Uluslararası İlişkiler Kuramlarında \\ Ana Akımlara Yeniden Bakış \\ Mustafa AYDIN* ve Sinem AKGÜL AÇIKMEŞE** \\ * Prof. Dr., Kadir Has Üniversitesi, Uluslararası İlişkiler \\ Bölümü \\ ** Doç. Dr., Kadir Has Üniversitesi, Uluslararası İlişkiler \\ Bölümü
}

Bu makaleye atıf için: Aydın, Mustafa; Akgül Açıkmeşe, Sinem, "Uluslararası İlişkiler Kuramlarında Ana Akımlara Yeniden Bakış”, Uluslararası İlişkiler, Cilt 12, Sayı 46, s. 1-9.

Bu makalenin tüm hakları Uluslararası İlişkiler Konseyi Derneği’ne aittir. Önceden yazılı izin alınmadan hiç bir iletişim, kopyalama ya da yayın sistemi kullanılarak yeniden yayımlanamaz, çoğaltılamaz, dağıtılamaz, satılamaz veya herhangi bir şekilde kamunun ücretli/ücretsiz kullanımına sunulamaz. Akademik ve haber amaçlı kısa alıntılar bu kuralın dışındadır.

Aksi belirtilmediği sürece Uluslararası Illişkiler'de yayınlanan yazılarda belirtilen fikirler yalnızca yazarına/yazarlarına aittir. UİK Derneğini, editörleri ve diğer yazarları bağlamaz.

Uluslararası İlişkiler Konseyi Derneği | Uluslararası İlişkiler Dergisi

Web: www.uidergisi.com.tr | E- Posta: bilgi@uidergisi.com.tr 


\title{
Uluslararası İlişkiler Kuramlarında Ana Akımlara Yeniden Bakış
}

\author{
Mustafa AYDIN \\ Prof.Dr., Uluslararast Ilişkiler Bölümü, Kadir Has Üniversitesi, İstanbul. E-Posta: maydin@khas.edu.tr \\ Sinem AKGÜL AÇIKMEŞE \\ Doç.Dr., Uluslararast Ilişkiler Bölümü, Kadir Has Üniversitesi, İstanbul. E-posta: sacikmese@khas.edu.tr.
}

\section{ÖZET}

Uluslararası İlişkiler’ in (Uİ) “büyük tartışma”larının sona erdiğine dair görüş alanın yazarlarının büyük çoğunluğu tarafından dile getirilmektedir. Bugün disiplinin ana dergilerinde büyük kuramsal tartışmalara yapılan atıflar önemli ölçüde azalmıştır ve en kayda değer münazaralar kuramlar/paradigmalar arasında değil, daha ziyade aynı kuramı benimseyen yazarlar arasında sıklıkla da ampirik çalışmalar üzerinden gerçekleşmektedir. Bu çalışma, Uluslararası İlişkiler' in "büyük tartışma"larının sakıncalarını ve Uİ yazınındaki "büyük tartışma”lara geri dönüş sorgulamalarını ortaya koyarak, Uİnin dünyada ve Türkiye'deki mevcut durumu ve geleceğine dair görüşler içermektedir. Bu noktadan hareketle, bu çalışma "büyük tartışma”lara bugüne kadar konu olan ve gelecekteki tartışmaların da temelini oluşturacak ana akımları okuyuculara yeniden hatırlatmak üzere hazırlanan bu özel sayıya giriş makalesi olarak kaleme alınmıştır.

Anahtar Kelimeler: Uluslararası İlişkiler, Disiplin, Kuram, Büyük Tartışma, Paradigma.

\section{Revisiting the Mainstream Approaches of the Theories of International Relations}

\begin{abstract}
The view that we have reached the end of the "grand debates" in International Relations (IR) is widespread among the majority of IR scholars. Today, we observe that the references to the great theoretical debates in the prominent journals of IR have significantly diminished and that the most relevant debates have been among the scholars belonging to the same school specifically over empirical studies rather than between theories/paradigms. This paper, by revealing the challenges generated by the "grand debates" and the discussions on whether or not there will a return to the "grand debates", incorporates some ideas on the current status as well as the future of IR in Turkey and the world. Taking from this point, this paper has been prepared as an introductory article to this special issue which has been compiled in order to remind the readers on the mainstream theories of IR that have been subject to the "grand debates" and that will shape the future discussions on the state of the IR theory.
\end{abstract}

Keywords: International Relations, Discipline, Theory, Grand Debate, Paradigm. 
Uluslararası İlişkiler disiplininin tarihine damga vurmuş "büyük tartışma” silsilelerinin günümüzde artık sona erdiği Uluslararası İlişkiler yazarlarının büyük kısmı tarafından benimsenen bir görüş. $\mathrm{Bu}$ kapsamda, 1970'lerin sonunda Kenneth Waltz'in The Theory of International Politics başlıklı kitabının yayınlanmasını takiben alevlenen paradigmalar (Gerçekçi, çoğulcu, yapısalcı) arası çekişme ile bazılarının “üçüncü büyük tartışma” olarak gördükleri pozitivizm ile pozitivizm-sonrası yöntemler arasındaki tartışmanın artık neredeyse tamamen yatıştığını söylemek mümkün. ${ }^{1}$ Hatta o kadar ki, 1996'da Ole Wæver'ın ABD'de hâkim olan akılcı (yeni-gerçekçilik ve yeni-liberalizmin birleştiği "neo-neo" sentezi olarak tanımlanan pozitivist) yaklaşımlar ile Avrupa'da başat nitelik taşıyan yansıtmacı (reflectivist) kuramlar (eleştirel kuram, post-yapısalcılık, post-modernizm, inşacılık ve feminizm) arasında gerçekleştiğini savunduğu "dördüncü büyük tartışma" dahi güncelliğini yitirdi. ${ }^{2}$ Bugün disiplinin dergilerinde büyük kuramsal tartışmalara yapılan atıflar bir hayli azalmış durumda ve en kayda değer münazaralar kuramlar/paradigmalar arasında değil, daha ziyade aynı kuramı benimseyen yazarlar arasında sıklıkla da ampirik çalışmalar üzerinden gerçekleşiyor. ${ }^{3}$

Zaten büyük tartışmaların sona ermesiyle eş zamanlı olarak, Uluslararası İlişkiler yazarlarının yeni kuramlar aramak/geliştirmek yerine, mevcut kuramları ampirik metotlarla test etmeye yönelmesi sık rastlanan bir duruma haline geldi. Bunun sonucunda da, bir zamanlar çok arzulandığı gibi, disiplin herhangi bir kuramın diğeri üzerinde baskın olmaya çalışmadığı, fakat aynı anda pek çok kuramı içinde barındıran çoğulcu bir yapıya bürünmeye başladı. ${ }^{4}$ Öte yandan, bu durumu "kuramsal barış" olarak tanımladıkları makalelerinde, Tim Dunne, Lene Hansen ve Colin Wight, paradigma savaşlarının sona erdiği bu çeşitlilik ortamını Uluslararası İlişkiler teorisinin sonunun gelip gelmediği sorusuyla karşıliyorlar. ${ }^{5}$

Bize göre, ana akımlar arasındaki "büyük” (grand) tartışmaların azalması ile Uluslararası İlişkiler kuramının araştırma alanı olarak önemini kaybettiğine dair bir yorum yanıltıcıdır. Nitekim çoğulculuk döneminin yazını incelendiğinde bunun tersine sonuçlara ulaşmak mümkün. Örneğin, Pınar Bilgin ve Bahar Rumelili, "inşacı, tarihsel, toplumsal, post-yapısalcı ve post-kolonyal gibi çeşitli kategorilere ayrılan eleştirel yaklaşımların güç, güvenlik, barış gibi temel kavramların hâkim tanımlarının hem yeterliliğini, hem de normatif sonuçlarını sorgulayarak, Uluslararası İlişkiler kuramı çalışmalarına yeni bir ivme kazandırdıklarını" savunuyorlar. ${ }^{6}$ Ayrıca, bu döneme damgasını vuran belirli siyasal olgulara birçok farklı değişkenle odaklanan ve daha çok hipotez sınama işlevini yerine getirmeyi amaçlayan orta-büyüklükteki kuramların (mid-range theories) geliştiği, çeşitlendiği ve ampirik olarak test edildiği akademik çalışmaların varlığı da göz ardı edilemez. Nitekim, ABD kökenli International Organization (IO), American Political Science Review (APSR) ve International Studies Quarterly (ISQ) gibi dergilerde yayınlanan makaleler arasında bu tür neden-sonuç ilişkisini irdeleyen ve ampirik analiz-

1 Tim Dunne, Lene Hansen ve Colin Wight, “The End of International Relations Theory?”, European Journal of International Relations, Cilt 19, No.3, 2013, s.406.

2 Ole Wæver, 'The Rise and Fall of the Inter-paradigm Debate”, Steve Smith, Ken Booth ve Marysia Zalewski (der.), International Theory: Positivism and Beyond, Cambridge, Cambridge University Press, 1996, s.163-164. Akılc1 yaklaşımların ortak özellikleri hakkında genel bir değerlendirme için bkz., Steve Smith, “The Discipline of International Relations: Still an American Social Science?”, The British Journal of Politics and International Relations, Cilt 2, No.3, 2000, s.379-383.

3 Ole Wæver, “Still a Discipline After All These Debates?”, Tim Dunne, Milja Kurki ve Steve Smith (der.), International Relations Theories: Discipline and Diversity, Oxford, Oxford University Press, 2013, s.319.

4 Çoğulculuk tartışması için bkz., Nicholas Rengger, "Pluralism in International Relations Theory: Three Questions", International Studies Perspectives, Cilt 16, No.1, 2015, s.32-39.

5 Dunne, Hansen ve Wight, “The End of International Relations Theory”, s. 406.

6 Pınar Bilgin ve Bahar Rumelili, “Editörden”, Uluslararası İlişkiler, Cilt 8, No.29 ("Uluslararası İlişkilerde Temel Kavramları Yeniden Düşünmek” başlıklı özel sayı), 2011, s.1. 
ler eliyle hipotez sınama işlevini yerine getiren araştırmalar çoğunluğu oluşturuyor. ${ }^{7}$ Bunların varlığı, kuramlaşmanın sona ermediğini, meta-teorik arayışlardan ziyade mezo düzeyde açıklamalarla büyük tartışmaların boş bıraktığı alanların doldurulmaya çalışıldığına ve öne çıkan ampirizmle birlikte bir anlamda "bilimselleşmeye" yapılan vurgulara işaret ediyor.

Ortaya çıkan bu yeni durum, diğer taraftan, Uluslararası İlişkilerin akademik bir disiplin veya Siyaset Bilimi alanının bir alt dalı olarak diğer sosyal ve beşeri bilimlerle ilişkisinin de yeniden mercek altına alınmasını gerektirmiştir. Bilindiği üzere, özellikle ana akım Uluslararası İlişkiler kuramlarının gelişiminde diğer sosyal ve beşeri bilim alanlarının önemli etkisi olmuştur. Özellikle disiplinin kurumsallaşmasını takip eden yıllarda tarih, hukuk ve siyaset bilimi kökenli akademisyenler ile iktisat, psikoloji ve sosyoloji kökenliler Uluslararası İlişkiler disiplinine dair çalışmalar yapmışlardır. ${ }^{8}$ Fakat, Uluslararası İliş̧kiler'in başka disiplinlerden ciddi miktarda kavram ithal etmesine rağmen, diğer disiplinlerin Uluslararası İlişkiler kavramlarını nadir biçimde kullanmaları disiplinin anlamı ve etkinliği açısından önemli bir sorun olarak algılanmış ve Uluslararası İlişkiler kuramının yeterliliği, bilimselliği ve sınırlarının sorgulanmasına neden olmuştur. ${ }^{9}$ Bu sorgulamada belki de en ileri nokta, Nicholas Onuf'un da Theory-Talks platformunda altını çizdiği, "konusu bulunmayan” Uluslararası İlişkiler'in "disipliner bir proje olarak başarısız" olduğuna dair yorumdur. ${ }^{10}$

Bu içerik, anlam ve bilimsellik tartışmalarına paralel olarak, Uluslararası İlişkiler kuramları üzerinde pozitivist ekolün halen çok güçlü olmasının temelinde Uluslararası İlişkiler'in genel bilim felsefesindeki gelişmeleri yakından takip edememesinin yattığı iddia edilmektedir. Özellikle biyoloji ve fizik alanındaki gelişmeler bilim dünyasının genel-geçer evrensel yasalara inancını kökten sarsarken, ${ }^{11}$ bu tartışmanın sosyal bilimlere ve ardından da Uluslararası İlişkiler alanına nüfuz etmesi disiplinin varlığına zarar verebilecek kadar geç gerçekleşmiştir. ${ }^{12} \mathrm{Bu}$ çerçevede, giderek çoğulcu bir yapıya bürünen Uluslararası İlişkiler' in sosyal bilimlerdeki yeri de sorgulanmaya açılmıştır. ${ }^{13}$

Bu noktada, Uluslararası İlişkiler disiplininin karşısındaki bir diğer sorunun, alanın disipliner ve bilimsel başarı/sızlığına ek olarak, başta post-pozitivist kuramlar olmak üzere yeni "katılımcıların” alana getirdiği çoğulculuğun hangi ölçüde ve nasıl kabul edilip, disipline içselleştirileceğine ilişkin olduğu vurgulanmalıdır. Robert Keohane, International Studies Association' in 1988'deki yıllık kongresin-

7 Patrick Thaddeus Jackson ve Daniel H. Nexon, “I Can Has IR Theory?” The Duck of Minerva Working Paper, No.1,2013, http://www.duckofminerva.com/wp-content/uploads/2012/10/Jackson-Nexon-DoM-WP-1.2013.pdf, p. 5 (Erişim Tarihi: 30 Mayıs 2015).

8 Örneğin bkz. Hans Morgenthau, Politics Among Nations: The Struggle for Power and Peace, New York, McGraw-Hill, 1948; Paul Kecskemeti, Strategic Surrender: The Politics of Victory and Defeat, Stanford University Press, 1958; Thomas Schelling, Strategy of Conflict, Mass., Harvard University Press, 1960; Immanuel Wallerstein, World-Systems Analysis: An Introduction, Durham, Duke University Press 2004; Morgenthau hukuk, Kecskemeti psikoloji, Schelling iktisat, Wallerstein ise sosyoloji kökenlidir.

9 Richard Little ve Barry Buzan, "Why International Relations has Failed as an Intellectual Project and What to do about it”, Millenium - Journal of International Studies, Cilt 30, No.1, 2011, s.19-39. Ayrica bkz., Ilan Zvi Baron, “The Continuing Failure of International Relations and the Challenges of Disciplinary Boundaries”, Millennium- Journal of International Studies, Cilt 43, No.1, 2014, s.224-244.

10 P. Schouten, “Theory Talk No 70: Nicholas Onuf on the Evolution of Social Constructivism, Turns in IR and a Discipline of Our Making”, Theory Talks, 2 Temmuz 2015, http://www.theory-talks.org/2009/03/theory-talk-27.html (Erişim Tarihi: 10 Temmuz 2015).

11 Robert W. Cox, “The Point is not Just to Explain the World but to Change It", Christian Reus-Smit ve Duncan Snidal (der.), The Oxford Handbook of International Relations, Oxford, Oxford University Press, 2010, s.88.

12 Smith, "Introduction", s.15

$13 \mathrm{Bu}$ tartışmalar için bkz. Iver B. Neumann, "International Relations as a Social Science”, Millennium: Journal of International Studies, Cilt 43, No.1, 2014, s.330-350; Chris Brown, "IR as a Social Science: A Response", Millennium: Journal of International Studies, Cilt 43, No.1, 2014, s.351-354. 
de yaptığı meşhur konuşmada yeni gelişen ve çoğunluğu orta-büyüklükte kuramlar olarak bilinen bu akımlara karşı çok sert eleştiriler getirmiş ve bunların ciddi şekilde gözden geçirilmedikleri takdirde disiplinin merkezinde yer alamayacaklarını iddia etmişti. ${ }^{14}$ Nitekim bugün gelinen noktada, yeni akımların disiplin içinde kabullenilmesi önemli bir sorun olarak ortaya çıkmış ve Gerçekçilik, Liberalizm veya İnşacılık gibi ana akımların dışında kalan yaklaşımların kuramsal araştırmalardan dışlanması sık rastlanan bir duruma dönüşmüştür. ${ }^{15}$ Örneğin, daha sonra gelişen çoğulcu ortamda akademide çalış1lan sorunlar ile siyasa üretimi arasındaki makasın gitgide açıldığını savunan Stephen M. Walt, ${ }^{16}$ dünya politikalarını anlamak ve açıklamak için Gerçekçilik, Liberalizm ve İnşacılık kuramlarından oluşan bir sınırı çoğulculuğun limiti olarak benimsemiştir. ${ }^{17}$

Kuramsal çerçevenin parçalanmışlık olarak da etiketlenebilecek şekilde çeşitlenmesi, Uluslararası İlişkiler kuramlarının günümüzde ve gelecekte nasıl incelenmeleri gerektiği konusunda bir tartışmayı da beraberinde getirmektedir. Uluslararası İlişkiler kuramlarını, Cox'un eleştirel teori/ sorun çözme teorileri ayrımı ile ${ }^{18}$ araştırma yöntemlerine göre (akılcı ve pozitivist yaklaşımlara karşı sosyal-yorumsamacı yaklaşımlar) gruplandırarak veya coğrafi ekollere göre (ABD'de akılcı ve pozivist, Avrupa'da sosyal teoriler) sınıflandırarak incelemek mümkünse de, ${ }^{19}$ Uluslararası İlişkiler kuramlarının çalışılmasında en çok -süreleri, sayıları ve içerikleri tartışmalı olmakla beraberbir dizi "büyük tartışma” kategorisinden yararlanıldığı görülmektedir. Yine de, Nuri Yurdusev'in "konvansiyonel anlatı” ya da "ardışık münazaralar” olarak betimlediği bu yöntem birkaç yönden sorunludur. ${ }^{20}$ Öncelikle, yazarların belli başlı "kamplara” ayrılması her ne kadar Uluslararası İlişkiler kuramlarının öğrenilmesini kolaylaştırsa da, önemli pek çok yazar, fikirlerinin akademik kariyerleri boyunca ciddi değişimlere uğramasına rağmen sadece bir veya iki eseriyle anılmakta ya da zaman içinde yerleri değişse de, orijinal görüşlerinin onları konumlandırdığı çerçevede anılmaktadırlar. Her ne kadar bu şekilde birden fazla "anlatı"nın parçası olabilecek akademisyen sayısı bir elin parmaklarını geçemiyorsa da, bu tür yazarların farklı dönemlerde farklı görüşleri savunan çalışmalarını özellikle disiplinin yenilerine ikilemler şeklinde sunulan "büyük tartışmalar” kapsamında anlatmak sorunlu olmaktadir.

Öte yandan, Smith’e göre sözü edilen “tartışma”ların kapsamı çoğunlukla abartılmaktadır; zira aslında Gerçekçi kuram disiplin üzerinde baskın bir etkiye sahipken, Liberal veya Marksist anlayış ikincil niteliktedir. ${ }^{21}$ Dolayısıyla aslında ortada "büyük tartışma" da yoktur. Bu durum, Gerçekçi anlayışa karşı çıkan kuramların kimi zaman sorunlu bir şekilde tanımlanmalarına neden olmuştur. Örneğin, 1945'e kadar olan dönemde "idealist" yazarların Uluslararası İlişkilerde "güç" gibi temel kav-

14 Robert O. Keohane, “International Institutions: Two Approaches” International Studies Quarterly, Cilt 32, Say1 4, 1988, s.379-396.

15 Bkz. Jack Synder, “One World, Rival Theories” Foreign Policy, 26 Kasım 2009, http://foreignpolicy.com/2009/10/26/ one-world-rival-theories/ (Erişim Tarihi: 22 Nisan 2015).

16 Stephen M. Walt, “The Relationship Between Theory and Policy in International Relations” Annual Review of Political Science, No.8, 2005, s.23-48.

17 Stephen M. Walt, “One World, Many Theories”, Foreign Policy, No.110, 1988, p.29-46.

18 Robert W. Cox, "Social Forces, States and World Orders: Beyond International Relations Theory” Millenium - Journal of International Studies, Cilt 10, No.2, 1981, s.128-129.

19 P. Schouten, "Theory Talk No 27: Christian Reus-Smit on IR Cultures, Re-thinking IR and Bridging the NormativeEmpirical Divide, Theory Talks, 24 Mart 2009, http://www.theory-talks.org/2009/03/theory-talk-27.html (Erişim Tarihi: 30 Mayss 2015).

20 Nuri Yurdusev, “Uluslararası İlişkilere Teorik Bakmak”, Uluslararası İlişkiler, Cilt 2, Sayı 6, 2005, s.162.

21 Steve Smith, "Introduction: Diversity and Disciplinarity in International Relations Theory”, Tim Dunne, Milja Kurki ve Steve Smith (der.), International Relations Theories: Discipline and Diversity, Oxford, Oxford University Press, 2013 , s.4. 
ramları göz ardı ettiği görüşü tartışmalı olmasına rağmen çok yaygındır.22 Ayrıca, Gerçekçi kuramın antik Yunan’a uzanan bir geleneği temsil ettiği ve Uluslararası İlişkiler kuramları arasında özel bir yeri olduğuna dair inanç, farklı kuramlar arasındaki diyaloğu sıkça sekteye uğratmaktadır. ${ }^{23}$

Son olarak, Yurdusev'in de belirttiği gibi Uluslararası İlişkiler analizlerini sınırlı tutan büyük tartışmalarda, "bazı teori ve teorisyenlere özellikle Atlantik'in doğu yakasındakilere, hiç yer yoktur... Aslında söz konusu tartışmalar daha çok Atlantik'in batı yakasındaki camianın tartışmalarıdır”. ${ }^{24}$ $\mathrm{Bu}$ kapsamda ABD merkezli akademisyenlerin Uluslararası İlişkiler'in gelişiminde oynadıkları etkin rolün disiplin üzerindeki olumlu/olumsuz sonuçlarının uzun süredir tartışma konusu olduğunu hatırlamalıyız. ${ }^{25}$ Peter Harris, ABD ve İngiltere'de yayımlanan Uluslararası İlişkiler ders kitaplarını karşılaştırdığı bir çalışmasında, bu kitapların benzer konular üzerinde dursalar dahi bunları ele alma şekillerinin çok farklı olduğu, bunun da disiplin içi bölgesel bölünmelere işaret ettiği sonucuna varmıştır. Buna göre, Atlantik'in iki yakasında yazılmış farklı iki kitaba göre şekillendirilen müfredatlar ışığında eğitim görecek iki öğrenci, Uluslararası İlişkiler disiplininin ne olduğu ve amacı konusunda farklı fikirler edinecektir. ${ }^{26}$ Benzer şekilde, örneğin, uzun süre büyük ölçüde Amerikan-merkezli olarak ve Gerçekçi yaklaşımın yoğun etkisi altında gelişen Stratejik Çalışmalar alanında da 1980’lere kadar, strateji neredeyse tüm dünyada "Amerika'dan kopyalanarak" çalışılmış, ${ }^{27}$ bağımsız stratejik çalışmalar ya Sovyetler Birliği örneğinde olduğu gibi asker-güdümlü ya da Avrupa örneğinde olduğu gibi istisnaî kalmıştır. $^{28}$ Bu durum, özellikle ABD dışından Uluslararası İlişkiler kuramına yapılan katkıları büyük ölçüde sınırlamaktadır.

Tüm bu eleştirilerin bizi getirdiği nokta, paradigmatik kuramsal tartışmaların yararsızlığına dair inanç ç $^{29}$ ile büyük tartışmaların geleceğinin olmadığına dair kanaattir. Buna karşılık, kuramlar hakkındaki büyük tartışmaların Uluslararası İlişkiler’i tanımladığını ve şekillendirdiğini savunarak, alanın kimlik sorununun çözümü için büyük tartışmalara ihtiyaç olduğunu ifade eden yazarlar da vardır. ${ }^{30}$ Hatta Dunne/Hansen/Wight tarafından da vurgulandığı üzere, kimileri kuramsal çeşitliliğin aslında geçici bir durum olduğunu, kuramsal büyük tartışmalara geri dönüş yaşanabileceğini ve çoğulcu dönemin bunun için bir araç vazifesi göreceğini iddia etmektedirler. ${ }^{31}$ Bir başka deyişle, günümüzün Uluslararası İlişkiler yazını hala büyük tartışmalara geri dönüşün mümkün ya da gerekli olup olmadığı ile ilgilenmekte, hatta belki de bu sorgulamalara gelecekten bakıldığında bunun da yeni bir "büyük tartışma” silsilesi olarak nitelendirilebileceği akla gelmektedir. Bu çerçevede, elinizdeki özel sayı, büyük tartışmalara bugüne kadar konu olan ve gelecekteki tartışmaların da çıkış noktasını oluşturacak ana

22 Andreas Osiander, "Rereading Early Twentieth-Century IR Theory: Idealism Revisited” International Studies Quarterly, Cilt 42, No.3, s.412.

23 Michael C. Williams, The Realist Tradition and the Limits of International Relations, Cambridge, Cambridge University Press, 2005, s.128.

24 Yurdusev, "Uluslararası İlişkilere Teorik Bakmak”, s.162-163.

25 Bkz. Stanley Hoffman, “An American Social Science: International Relations”, Daedalus, Cilt 106, No.3, 1977.

26 Peter Harris, “The Transatlantic Divide in (Undergraduate) International Relations”, Journal of Transatlantic Studies, Cilt 12, No.2, 2014, s.234.

27 Ole Wæver ve Barry Buzan, "After the Return to Theory: The Past, Present, and Future of Security Studies", Alan Collins (der.), Contemporary Security Studies, Oxford, Oxford University Press, 2007, s.393.

28 Stratejik Çalışmaların Üçüncü Dünyada, SSCB ve Avrupa’da istisnaî gelişimi için bkz. Ken Booth ve Eric Herring, Keyguide to Information Sources in Strategic Studies, Londra, Mansell, 1994, s.10; Wæver ve Buzan, "After the Return to Theory", s.391-392.

29 Chris Brown, "Situating Critical Realism”, Millenium - Journal of International Studies, Cilt 35, No.2, 2007 , s.409.

30 Bkz. Brian C. Schmidt, “The End of Great Debates?”, http://www.e-ir.info/2014/02/02/the-end-of-great-debates/, 2 Şubat 2014 (Erişim Tarihi: 30 Mayıs 2015).

31 Dunne, Hansen ve Wight, “The End of International Relations Theory?”, s.415. 
akımları yeniden hatırlatmak ve disiplindeki çoğulculuk döneminde ana akımların güncel tartışmalarını okuyuculara aktarmak amaciyla hazırland. ${ }^{32}$

Bu genel amaca ek olarak, Türkiye’deki ve Türkçe Uluslararası İlişkiler yazınına katkı sağlama hedefi de bu özel sayının ortaya çıkışında belirleyici olmuştur. Uluslararası İlişkiler kuramının Türkiye'deki ele alınış biçimi disiplinin genelinde merkez-çevre ekseninde yaşanan sorunları büyük ölçüde yansıttığından, Türkiye'deki Uluslararası İlişkiler kuramlarına dair çalışmaların zayıflı̆ıından rahatlıkla söz edilebilir. Bu çerçevede, ülkede hâkim olan geleneksel anlayış doğrultusunda, yeni kuramların geliştirilmesi göz ardı edilerek, yaygın olarak pratik sorunlara çözüm üretilmesi desteklenmektedir. ${ }^{33} \mathrm{Ni}$ tekim "çevre” ülke olarak kabul edilen Türkiye'deki Uluslararası İlişkiler yazınına bakıldığında, genel itibarıyla "merkez"den ödünç alınan kuram ve kavramların örnek olaylara uygulandığı, fakat bu kuram ve kavramların yeterlilikleri ve açıklama güçlerinin Türkiye örneğinden yola çıkarak sorgulanmasının pek yapılmadığı görülür. ${ }^{34}$ Her ne kadar uluslararası alandaki ileri düzey kuramsal tartışmalara katılan ve katkı sağlayan Türkiye'de yerleşik küçük ama üretken bir grup varsa da, bunların dışında kalan kayda değer sayıdaki eserin kuramsal yeterliliği şüphelidir. ${ }^{35}$ Bilgin bu durumun nedenleriyle ilgili olarak Uluslararası İlişkilerin Türkiye'deki gelişim sürecine dikkat çekmekte ve bu süreçte Uluslararası İlişkiler teorisinin, tarih ve hukuk alanlarındaki tartışmanın gerisinde kaldığını belirtmektedir. ${ }^{36}$ Buna ek olarak, Türkiye'deki Uluslararası İlişkiler kuramsal tartışmaları uzun süre büyük ölçüde Gerçekçi kuramın sınırları içinde kalmış, Hans Morgenthau tarafından temsil edilen Klasik Gerçekçilik en başından alandaki çalışmalar üzerinde hâkimiyet kurmuş ve Yeni-Gerçekçi akımla birlikte gelenekselcilik-davranışsalcılık tartışması neredeyse tamamen es geçilmiştir. ${ }^{37}$

Türkiye deneyiminden yararlanılarak yapılacak kuramsal ve kavramsal eleştiri ve katkılar hiç şüphesiz küresel kuramsal tartışmaların bir parçası olabilecektir. ${ }^{38}$ Fakat özgün kuramsal yazın oluşturmanın uzun bir süreç ve çaba gerektirmesi bir yana, küresel tartışmaların bu katkıya ne kadar izin vereceği de ayrı bir soru olarak ortada durmaktadır. Birçok ana akım yazar, en güçlü devletler haricinde bir birimden yola çıkarak bir kuram oluşturmanın anlamsız olduğunu savunma eğilimdedir. ${ }^{39} \mathrm{Bu}$ görüş kuramsal tutarlılık için ödenmesi gereken bir bedel olarak görülebilir; fakat eleştiriden bağımsız olarak kabul edilemez. Büyük güçlere olan aşırı ilgi, merkez-dışı (Anglo-Sakson dünyasının dışında kalan) bölgelerden türeyen/türetilen kuramların genelde ilgi görmemesine ${ }^{40}$ ve tam da bu nedenle

32 Bu özel sayı için, Uluslararası İlişkiler Dergisi’nin bundan önceki sayılarında ayrıntılı biçimde ele alınmadığı düşünülen kuramlar seçilmiş; ana akımlar arasında değerlendirilen Gerçekçilik bu nedenle kapsam dışı bırakılmıştır. Gerçekçilik ile ilgili olarak önceki sayılarda yayınlanan çalışmalar için bkz., Mustafa Aydın, "Uluslararası İlişkilerin Gerçekçi Teorisi: Kökeni, Kapsamı, Kritiği”, Uluslararası İlişkiler, Cilt 1, Sayı 1, 2004, s.33-60; Faruk Yalvaç, "Eleştirel Gerçekçilik: Uluslararası İlişkiler Kuramında Post-Pozitivizm Sonrası Aşama”, Uluslararası İlişkiler, Cilt 6, Sayı 24, 2010, s.3-32.

33 Mustafa Aydın, “Türkiye’de Uluslararası İlişkiler Çalışmaları ve Eğitimi Toplantı Tutanakları - Dördüncü Oturum” Uluslararası İlişkiler, Cilt 2, Sayı 6, 2005, s.26.

34 Pınar Bilgin, “Uluslararası İlişkiler Çalışmalarında 'Merkez-Çevre’: Türkiye Nerede?”, Uluslararası İlişkiler, Cilt 2, Sayı 6, 2005, s.10.

35 Aydın, “Türkiye'de Uluslararası İlişkiler Çalışmaları”, s. 27.

36 Pınar Bilgin, “Türkiye’de Jeopolitik Dogma”, Murat Yeşiltaş vd. (der.), Türkiye Dünyanın Neresinde? Hayali Coğrafyalar, Çarpışan Anlatılar, İstanbul, Koç Üniversitesi Yayınları, 2015, s.50-51.

37 İlhan Uzgel, “Türk Dış Politikası Yazımında Siyaset, Ayrışma ve Dönüşüm” Uluslararası İlişkiler, Cilt 4, Sayı 13, 2007, s.115-118.

38 Ersel Aydınlı ve Julie Mathews, “Türkiye Uluslararası İlişkiler Disiplininde Özgün Kuram Potansiyeli: Anadolu Ekolünü Oluşturmak Mümkün mü?”, Uluslararası İlişkiler, Cilt 5, Sayı 17, 2008, s.161; Bilgin, “Uluslararası İlişkiler Çalışmalarında Merkez-Çevre”, s.11.

39 Yakın tarihli bir örnek için bkz. John J. Mearsheimer, The Tragedy of Great Power Politics, New York, WW Norton \& Company, 2001.

40 Arlene Tickner, "Seeing IR Differently: Notes from the Third World” Millenium - Journal of International Studies, Cilt 32, No.2, 2003, s.297. 
uluslararası sistemde öne çıkan birçok sorunun uzun süre göz ardı edilmesine neden olmaktadır. ${ }^{41} \mathrm{Bu}$ nedenle, özellikle çevre ülke örneklerinden yola çıkarak küresel tartışmalara katkıda bulunabilecek kuramsal çalışmaların yapılması ayrı bir önem arz eder. Bu kapsamda, elinizdeki özel sayı, farklı ana akımların güncel tartışmaları ile teorik düşüncenin günümüz dünyasındaki yansımalarını Türkiye’den küresel kuramsal tartışmalara yapılacak katkılar için temel oluşturacak şekilde ele almakta ve Türkçe yazına katkı sağlamaktadır.

Bu çerçevede, Nil Şatana tarafından kaleme alınan "Uluslararası İlişkilerde Bilimsellik, Metodoloji ve Yöntem” başlıklı ilk makale, sayıdaki diğer makalelerden farklı olarak bir kurama odaklanmak yerine, kuramlara içsel metodoloji tartışmalarına değiniyor. Makale analitik uzlaşmacılık anlayışından yola çıkarak, disiplinde önemli derecede kutuplaşmaya yol açan pozitivist ve post-pozitivist yaklaşımların alanda yarattığı ayrışmanın neden olduğu sorunları inceliyor.

Ana akım kuramlar arasında benimsenen ve liberal düşüncenin Uluslararası İlişkiler alanındaki kuramsal boyutunu temsil eden Liberalizmin tarihsel gelişiminin yanı sıra, güncel durumuna da değinen Lerna Yanık tarafından kaleme alınan “Liberalizm: Bir Yazın Değerlendirmesi” başlıklı çalışma ise, Liberal kuramın zengin yapısının günümüzde geçerliliğini korumasının temellerini irdeliyor. Takip eden çalışmada Sevilay Aksoy, "Rejim Teorileri” başlığı altında Liberal kuramın önemli unsurlarından biri olan ve ana akım kuramlarca kabul gören anarşik yapının varlığına rağmen devletler arasındaki işbirliğini açıklayıcı nitelikteki Rejim Teorilerine değiniyor. Ardından, Yeni-Liberal kuramın önemli temsilcileri Robert O. Keohane ve Joseph Nye'ın 1987'de International Organizations'da yayınlanan "Power and Interdependence Revisited" başlıklı makalelerinin çevirisine yer verilerek, güç ile karşılıklı bağımlılık kavramlarının değişen dünyadaki geçerliliği tartışılıyor.

“Eleştirel bir Literatür Değerlendirmesi: Dışlamadan Sınırlı Tanımaya Uluslararası İlişkiler Kuramları ve Marksizm” başlıklı makalede ise İlhan Uzgel ve Nazan Bedirhanoğlu daha çok sosyoloji alanıyla bağdaştırılan Marksist düşüncenin Uluslararası İlişkiler alanındaki kuramsal tartışmalardan yakın geçmişe kadar uzak kalmasının nedenlerini ve ardından tartışmaların bir parçası haline gelerek alana yaptığı katkıları anlatıyor. Takip eden çalışmada Mehmet Akif Okur, hegemonya kavramının Cox ve Gramsci'nin bakış açılarıyla değerlendirmesini okuyucuya sunuyor. "Gramsci, Cox ve Hegemonya: Yerelden Küresele, İktidarın Sosyolojisi Üzerine” başlıklı makale, Eleştirel yaklaşımın Uluslararası İlişkiler alanındaki kuramsal tartışmalara yaptığı katkının kapsamlı bir değerlendirmesini de içeriyor.

Senem Aydın Düzgit’in kaleme aldığı "Post-Yapısalcı Yaklaşımlar ve Uluslararası İlişkilerin Temel Kavramları” başlıklı makalede ise, Post-yapısalcı yaklaşımların kuramsal tartışmalara sunduğu alternatif bakış açıları ve bu perspektif ışığında dış politika ve kimlik kavramlarının algılanışları yer alıyor. Bu sayının son makalesinde Bahar Rumelili İnşacı kuramın bölgeselcilik alanındaki tartışmalarına ve varsayımlarına yer veriyor. "Bölgesecilik ve İnşacılık: Kazanımlar ve Vaatler” başlıklı makale, bölgeselcilik alanında ön planda bulunan ve daha çok gerçekçi varsayımlarla ilişkilendirilebilecek tartışmalara alternatif bir bakış açısı sunuyor.

Bu özel sayıya katkıda bulunan yazarların bizlere sunmuş oldukları görüşlerin Türkiye’de gelişimi yavaş olan Uluslararası İlişkiler kuramı yazına değerli katkılar sağlayacağına inanıyoruz. Bu kapsamda, bu özel sayıya katkıda bulunan tüm yazarlara, makaleleri büyük bir titizlikle değerlendiren hakemlere ve bu sayının hazırlanmasında emeği geçen Gökçe Silman Gezer ile Onur Kara’ya teşekkür ederiz. Keyifli okumalar dileriz.

41 Mohammed Ayoob, "Inequality and Theorizing in International Relations: The Case for Subaltern Realism”, International Studies Review, Cilt 4, No.3, 2002, s.30. 


\section{Kaynakça}

Aydın, Mustafa, “Türkiye’de Uluslararası İlişkiler Çalışmaları ve Eğitimi Toplantı Tutanakları - Dördüncü Oturum”, Uluslararası İlişkiler, Cilt 2, Sayı 6, 2005, s. 108-124.

Aydın, Mustafa, “Uluslararası İlişkilerin Gerçekçi Teorisi: Kökeni, Kapsamı, Kritiği”, Uluslararası İlişkiler, Cilt 1, No 1, 2004, s. 33-60.

Aydınlı, Ersel ve Julie Mathews, “Türkiye Uluslararası İlişkiler Disiplininde Özgün Kuram Potansiyeli: Anadolu Ekolünü Oluşturmak Mümkün mü?”, Uluslararası İlişkiler, Cilt 5, No 17, 2008, s. 161-187.

Ayoob, Mohammed, "Inequality and Theorizing in International Relations: The Case for Subaltern Realism", International Studies Review, Cilt 4, No 3, 2002, s. 27-48.

Baron, Ilan Zvi, “The Continuing Failure of International Relations and the Challenges of Disciplinary Boundaries", Millennium- Journal of International Studies, Cilt 43, No 1, 2014, s. 224-244.

Bilgin, Pınar ve Bahar Rumelili, “Editörden”, Uluslararası İlişkiler, Cilt 8, No 29, 2011, s. 1-4.

Bilgin, Pınar, “Türkiye’de Jeopolitik Dogma”, Murat Yeşiltaş vd. (der.), Türkiye Dünyanın Neresinde? Hayali Coğrafyalar, Çarpışan Anlatılar, İstanbul, Koç Üniversitesi Yayınları, 2015.

Bilgin, Pınar, “Uluslararası İlişkiler Çalışmalarında 'Merkez-Çevre’: Türkiye Nerede?”, Uluslararası İlişkiler, Cilt 2, No 6, 2005, s. 3-14.

Booth, Ken ve Eric Herring, Keyguide to Information Sources in Strategic Studies, Londra, Mansell, 1994.

Brown, Chris, "IR as a Social Science: A Response", Millennium: Journal of International Studies, Cilt 43, No 1, 2014, s. 351-354.

Brown, Chris, “Situating Critical Realism”, Millenium - Journal of International Studies, Cilt 35, No 2, 2007, s. 409-416.

Cox, Robert W., "The Point is not Just to Explain the World but to Change It", Christian Reus-Smit ve Duncan Snidal (der.), The Oxford Handbook of International Relations, Oxford, Oxford University Press, 2010, s. 84-93.

Cox, Robert W., "Social Forces, States and World Orders: Beyond International Relations Theory” Millenium Journal of International Studies, Cilt 10, No 2, 1981, s. 126-155.

Dunne, Tim, Lene Hansen ve Colin Wight, “The End of International Relations Theory?”, European Journal of International Relations, Cilt 19, No 3, 2013, s. 405-425.

Harris, Peter, “The Transatlantic Divide in (Undergraduate) International Relations”, Journal of Transatlantic Studies, Cilt 12, No 2, 2014, s. 229-335.

Hoffman, Stanley, “An American Social Science: International Relations”, Daedalus, Cilt 106, No 3, 1977, s. 41-60.

Jackson, Patrick Thaddeus ve Daniel H. Nexon, “I Can Has IR Theory?” The Duck of Minerva Working Paper, No 1., 2013, http://www.duckofminerva.com/wp-content/uploads/2012/10/Jackson-Nexon-DoMWP-1.2013.pdf, p. 5 (Erişim Tarihi: 30 Mayıs 2015).

Paul Kecskemeti, Strategic Surrender: The Politics of Victory and Defeat, Stanford University Press, 1958.

Keohane, Robert O., "International Institutions: Two Approaches" International Studies Quarterly, Cilt 32, Say1 4, 1988, s. 379-396.

Little, Richard ve Barry Buzan, "Why International Relations has Failed as an Intellectual Project and What to do about it”, Millenium - Journal of International Studies, Cilt 30, No 1, 2001, s. 19-39.

Mearsheimer, John J., The Tragedy of Great Power Politics, New York, WW Norton \& Company, 2001.

Morgenthau, Hans, Politics Among Nations: The Struggle for Power and Peace, New York, McGraw-Hill, 1948.

Neumann, Iver B., "International Relations as a Social Science”, Millennium: Journal of International Studies, Cilt 43, No 1, 2014, s. 330-350.

Osiander, Andreas, "Rereading Early Twentieth-Century IR Theory: Idealism Revisited”, International Studies Quarterly, Cilt 42, No 3, s. 409-432.

Rengger, Nicholas, "Pluralism in International Relations Theory: Three Questions", International Studies Perspectives, Cilt 16, No 1, 2015, s. 32-39. 
Schelling, Thomas, Strategy of Conflict, Mass., Harvard University Press, 1960.

Schmidt, Brian C., “The End of Great Debates?”, http://www.e-ir.info/2014/02/02/the-end-of-great-debates/, 2 Şubat 2014 (Erişim tarihi: 30 Mayıs 2015).

Schouten, P., "Theory Talk No 27: Christian Reus-Smit on IR Cultures, Re-thinking IR and Bridging the Normative-Empirical Divide, Theory Talks, 24 Mart 2009, http://www.theory-talks.org/2009/03/theorytalk-27.html (Erişim tarihi: $\quad 30$ Mayıs 2015).

Schouten, P., "Theory Talk No 70: Nicholas Onuf on the Evolution of Social Constructivism, Turns in IR and a Discipline of Our Making", Theory Talks, 2 Temmuz 2015, http://www.theory-talks.org/2009/03/theorytalk-27.html (Erişim tarihi: 10 Temmuz 2015).

Smith, Steve, "Introduction: Diversity and Disciplinarity in International Relations Theory", Tim Dunne, Milja Kurki ve Steve Smith (der.), International Relations Theories: Discipline and Diversity, Oxford, Oxford University Press, 2013, s. 1-13.

Smith, Steve, “The Discipline of International Relations: Still an American Social Science?", The British Journal of Politics and International Relations, Cilt 2, No 3, 2000, s. 374-402.

Synder, Jack, "One World, Rival Theories", Foreign Policy, 26 Kasım 2009, http://foreignpolicy. com/2009/10/26/one-world-rival-theories/ (Erişim Tarihi: 22 Nisan 2015).

Tickner, Arlene, "Seeing IR Differently: Notes from the Third World", Millenium - _ Journal of International Studies, Cilt 32, No 2, 2003, s. 295-324.

Uzgel, İlhan, “Türk Dış Politikası Yazımında Siyaset, Ayrışma ve Dönüşüm”, Uluslararası İlişkiler, Cilt 4, No 13, 2007, s. 113-127.

Wæver, Ole, 'The Rise and Fall of the Inter-paradigm Debate", Steve Smith, Ken Booth ve Marysia Zalewski (der.), International Theory: Positivism and Beyond, Cambridge, Cambridge University Press, 1996, s. 149185.

Wæver, Ole, “Still a Discipline After All These Debates?”, Tim Dunne, Milja Kurki ve Steve Smith (der.), International Relations Theories: Discipline and Diversity, Oxford, Oxford University Press, 2013, s. 306-328.

Wæver, Ole ve Barry Buzan, "After the Return to Theory: The Past, Present, and Future of Security Studies", Alan Collins (der.), Contemporary Security Studies, Oxford, Oxford University Press, 2007, s. 383-402.

Wallerstein, Immanuel, World-Systems Analysis: An Introduction, Durham, Duke University Press, 2004.

Walt, Stephen M., “One World, Many Theories”, Foreign Policy, No 110, 1988, p.29-46. 